\title{
An Assessment of Early Adopters of TCFD Disclosures: The Singapore Perspective
}

\author{
Lawrence Loh and Yvonne Yock* \\ Centre for Governance and Sustainability, NUS Business School, National University of Singapore, Singapore
}

Submission: September 28, 2021; Published: October 06, 2021

*Corresponding author: Yvonne Yock, Centre for Governance and Sustainability, NUS Business School, National University of Singapore, 15 Kent Ridge Drive, Singapore 119245, Singapore

Keywords: Climate change; Sustainability; Risk management; Greenhouse gas emissions; Temperature

\section{Opinion}

Listed entities and financial institutions in Singapore may soon be mandated to make climate-related financial disclosures. Most notably, these disclosures may be aligned to a set of standards accepted globally. This was the call of the Monetary Authority of Singapore in June this year. In a related way, the Singapore Exchange (SGX) has earlier mandated that its listed companies complete a yearly sustainability report, with various specific components required for reporting on a comply-or-explain basis. It is currently examining how climate-related disclosures may be fostered amongst these companies. Indeed, the MAS may soon consult the industry on making climate-related reporting specifically in line with the recommendations of the Task Force on Climate-related Financial Disclosures (TCFD). This is a comprehensive framework that is broadly accepted internationally.

To enable better flow of information by organizations on climate change, the Task Force on Climate-related Financial Disclosures (TCFD) has been established by the Financial Stability Board [1] to allow stakeholders to make informed decisions regarding climate-associated risks. The TCFD framework is fast gaining traction in the Asia Pacific region. Jurisdictions such as Australia, Hong Kong, Japan, mainland China, and New Zealand have either adopted this standard or are moving towards it. It is expected that the Monetary Authority of Singapore may soon consult the industry on making climate-related reporting, specifically in line with the TCFD guidelines. The TCFD framework covers four disclosure areas: governance, strategy, risk management, and metrics and targets. It also recommends the use of scenario-based analyses to ascertain the impacts of climate change based on temperature increase scenarios so that businesses can assimilate these analyses into their strategic decision-making.
A global analysis of 12,000 companies in 2020 by Moody's Analytics found that only 17 percent of the companies have reported climate-relevant information using the TCFD framework or similar, and there were wide variations in how companies reported that information [2]. In corporate Singapore, climate change reporting is still in the very early stage. Our research centre conducted an initial assessment of nine listed companies that made disclosures along the line of TCFD. These were drawn from the Sustainability Reporting Review 2021 [3] that we had just completed in collaboration with the Singapore Exchange.

Our analysis addresses the four areas of TCFD (Table $1 \& 2$ ).

Table 1: TCFD Disclosure Categories.

\begin{tabular}{|c|c|}
\hline \multicolumn{2}{|c|}{ Recommended Disclosure (Number of Elements) } \\
\hline \multirow{2}{*}{ Governance } & a) Board oversight (8) \\
\cline { 2 - 3 } Strategy & b) Management's Role (5) \\
\cline { 2 - 3 } & b) Risk and Opportunities (5) \\
\cline { 2 - 3 } & c) Resilience of Strategy (8) \\
\hline \multirow{3}{*}{ Risk } & a) Risk Identification and Assessment (5) \\
\cline { 2 - 3 } & b) Risk Management Processes (1) \\
\hline \multirow{3}{*}{$\begin{array}{c}\text { Metrics and } \\
\text { Targets }\end{array}$} & c) Integration into Overall Risk Management (1) \\
\cline { 2 - 3 } & a) Climate-related Metrics (6) \\
\cline { 2 - 3 } & b) Scope 1, 2, 3 GHG Emissions (5) \\
\hline
\end{tabular}

Source: Financial Stability Board [2]. Task force on climate-related financial disclosures: 2020 Status report. 
Table 2: Elements in TCFD Disclosures.

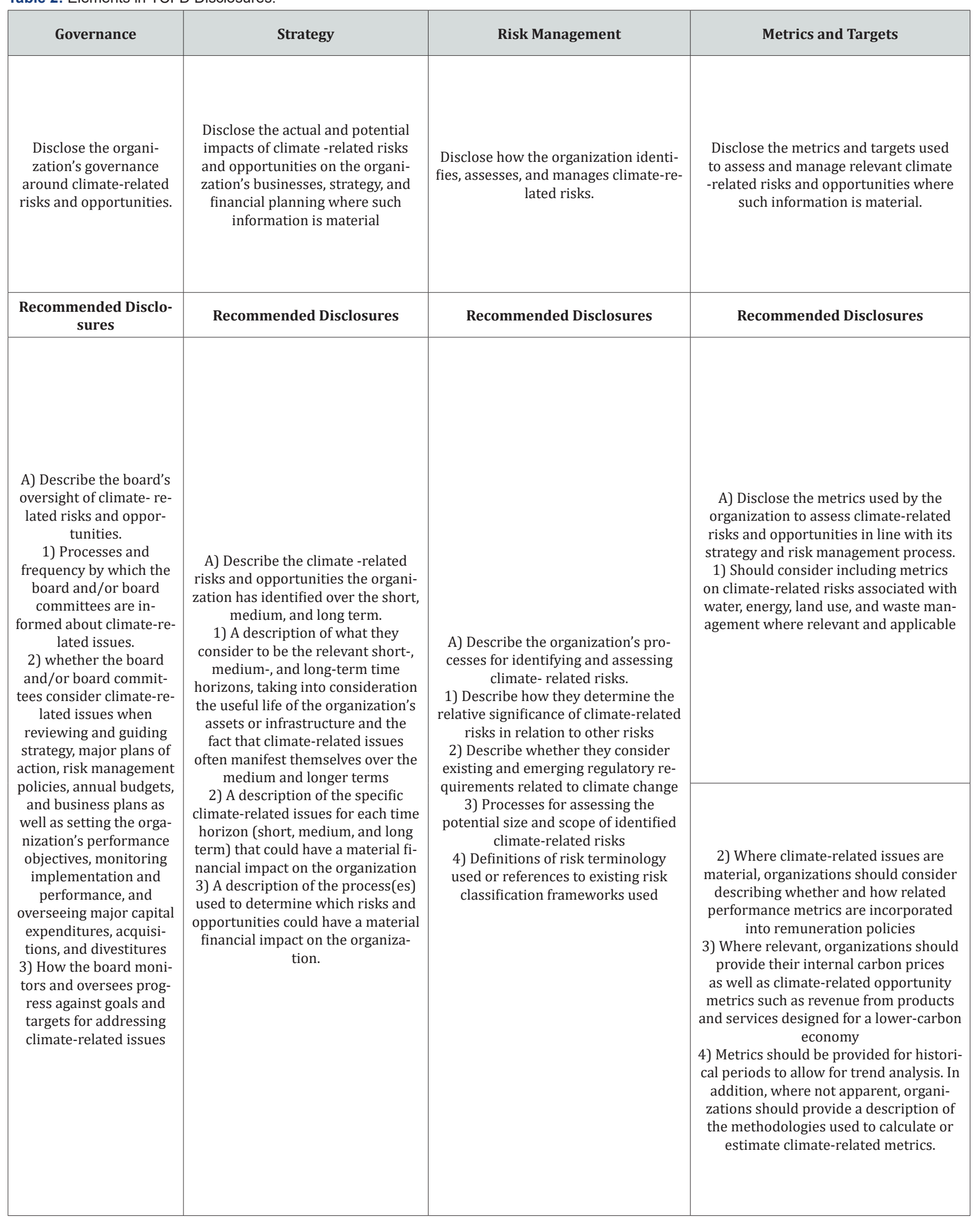


B) Describe management's role in assessing and managing climate-related risks and opportunities.

1) Whether the organization has assigned climate-related responsibilities to management-level positions or committees; and, if so, whether such management positions or committees report to the board or a committee of the board and whether those responsibilities include assessingand/or managing climate-related issues

2) A description of the associated organizational structure(s)

3) Processes by which management is informed about climate-related issues

4) How management (through specific positions and/or management committees) monitors climate-related issues
B) Describe the impact of climate-related risks and opportunities on the organization's businesses, strategy, and financial planning. 1) Organizations should consider including the impact on their businesses and strategy in the following areas: Products and services, supply chain and/or value chain, adaptation and mitigation activities, investment in research and development, operations (including types of operations and location of facilities)

2) Organizations should describe how climate-related issues serve as an input to their financial planning process, the time period(s) used, and how these risks and opportunities are prioritized in the following areas: Operating costs and revenues, capital expenditures and capital allocation, acquisitions or divestments, access to capital
B) Describe the organization's processes for managing climate-related risks.

1) Describe their processes for managing climate-related risks, including how they make decisions to mitigate, transfer, accept, or control those risks 2) Explain how materiality determinations are made within their organizations
B) Disclose Scope 1, Scope 2, and, if appropriate, Scope 3 greenhouse gas (GHG) emissions, and the related risks.

1) GHG emissions should be calculated in line with the GHG Protocol methodology to allow for aggregation and comparability across organizations and jurisdictions. As appropriate, organizations should consider providing related, generally accepted industry-specific GHG efficiency ratios.

2) GHG emissions and associated metrics should be provided for historical periods to allow for trend analysis
C) Describe the resilience of the organization's strategy, taking into consideration different climate-related scenarios, including a $2^{\circ} \mathrm{C}$ or lower scenario.

1) Where they believe their strategies may be affected by climate-related risks and opportunities

2) How their strategies might change to address such potential risks and opportunities

3) The climate-related scenarios and associated time horizon(s) considered
C) Describe how processes for identifying, assessing, and managing climate -related risks are integrated into the organization's overall risk management.
C) Describe the targets used by the organization to manage climate- related risks and opportunities and performance against targets

1) Such as those related to GHG emissions, water usage, energy usage, etc., in line with anticipated regulatory requirements or market constraints or other goals. Other goals may include efficiency or financial goals, financial loss tolerances, avoided GHG emissions through the entire product life cycle, or net revenue goals for products and services designed for a lower-carbon economy. 2) In describing their targets, organizations should consider including the following: whether the target is absolute or intensity based, time frames over which the target applies, base year from which progress is measured, key performance indicators used to assess progress against targets

Source: Financial Stability Board [2]. Task force on climate-related financial disclosures: 2020 Status report.

Table 1 covers the TCFD disclosure categories, Table 2 covers the elements in the TCFD disclosures, and Table 3 summarizes the analysis of nine companies that report according to TCFD disclosures. The full description of the elements described in Table 3 can be found in Table 2. 
Table 3: Analysis of companies on the TCFD disclosures framework.

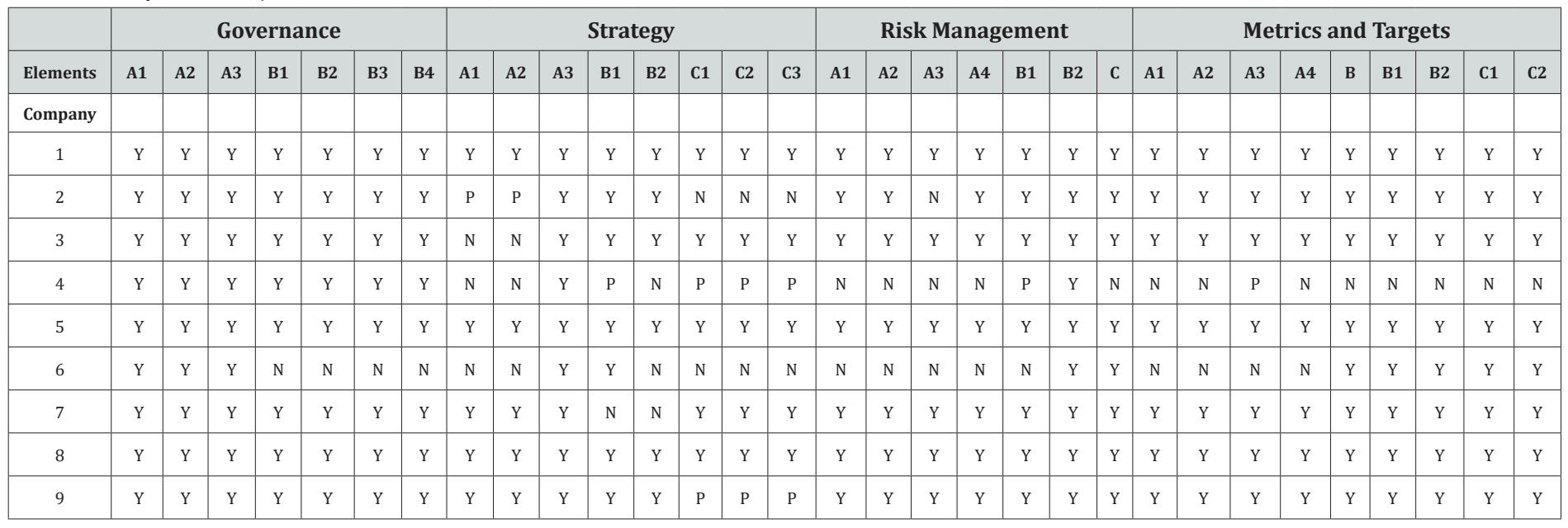

Notes. $\mathrm{Y}$ refers to Yes, this was report, $\mathrm{N}$ refers to No, this was not reported, and $\mathrm{P}$ refers to Partially reported.

From Table 3, we can see that the strategy element is the weakest link for most companies as information related to the strategy for dealing with climate change is only partially or not reported by many of the companies in our analysis. On the other hand, the governance element is the strongest suit for most companies as this element is the most reported by the companies in our analysis. While companies listed in the Singapore stock exchange are more adept at reporting issues related to governance and least adept at reporting issues related to strategy, we did not find the same trend for companies across other ASEAN countries. In our Corporate Sustainability Reporting in ASEAN Countries report [4], we found that companies in ASEAN countries were more adept at reporting issues related to materiality, risk and opportunities, and stakeholder engagement which falls under the strategy element, and they were least adept at disclosure related to governance. Having identified the disclosure areas that are the least reported and the most reported, the next few sections will identify the areas for improvement in each of the disclosure element.

First, the governance aspect covers the board's involvement in climate-related matters, including incorporating them in the business plans and having management supervise the responsibilities. We surmise that companies studied tend to have no difficulty in making the necessary disclosures.

Second, in the domain of strategy, companies are expected to discuss the impact of climate-related risks and opportunities on their businesses as well as the resilience in dealing with the risks. In our analysis, we found that companies were generally articulative of the climate-related risks that they face for their strategies. However, they did not describe the risks relative to various timeframes. Most companies did not conduct materiality analysis which would have helped them to identify the risks that are most pertinent to their stakeholders. In assessing the resilience of the company, only a few of the companies conducted scenario analyses of high emissions (up to 5 degrees Celsius) and low emissions (up to 2 degrees Celsius); however, they tended to provide scant information about how they would use results from such analyses to inform their business plans. In summary, it seems that the companies that we sampled are cognizant of the climate-related risks that can affect their businesses; however, they are less astute about the long-term impact of climate-related risks. Most companies also lack the ability to determine their organization's resilience to future climate uncertainties.

Third, in the process of risk management, companies did fare much better. They were generally able to explain the significance of climate-related risks relative to other risks, the scope and size of climate-related risks, and actions that they would take to mitigate these risks. Companies were able to discuss risk management as it involves a more structured set of actions that they had already been doing.

Fourth, in terms of metrics and targets, companies generally did a good job of disclosing them based on scope 1, scope 2, and scope 3 greenhouse gas (GHG) emissions. Some companies also included metrics and targets that might not be pertinent to the climate-related risks faced by them. As the companies cut across multiple industries, there were variations in the metrics and targets relevant to each specific industry. There were also different approaches on the use of time periods as diverse ranges were used by the companies.

On an overall basis, we found vast differences in how companies disclose using the TCFD framework. Some of the companies explained in their sustainability report how they applied the TCFD disclosure guidelines as a reference in their reporting, and yet other companies followed the TCFD disclosures on a detailed basis. Only a few companies used the future climate 
scenario outlined in the TCFD framework to illustrate future risks and opportunities. This seems to be the weakest link now although it is similar to what TCFD itself had highlighted - disclosures were lowest for resilience scenarios at only $7 \%$ of the companies that it studied [2].

In our analysis, there were perhaps two companies that may be worthy of illustration in their approaches to TCFD reporting as of now.

City Developments Limited (CDL), a notable pioneer in sustainability reporting, has a detailed standalone TCFD segment in its integrated sustainability report. CDL covers the sections in each of the TCFD areas adequately and refers readers to the pertinent sections if they want to dive deeper. It also provided the strategic rationale well for the targets it sets for the climate scenarios and the justification for identifying certain components that pose climate risks. The remarkable takeaway of CDL's TCFD report is the useful degree of specificity in the disclosures going beyond general noble statements that other companies may find more convenient to write.

Singapore Telecommunications Limited (Singtel) provides yet another model way for consideration even if many Singapore companies are only beginning to look at TCFD. Singtel has a detailed articulation of the company's climate action journey and the particular alignments to the four TCFD areas. It also shares informative views on climate risks, opportunities, and financial impact. What stands out is the scenario analysis based on an overseas operating environment. Singtel has even highlighted the detailed insights from a pilot exercise. This comes across as very candid and useful.

Thus far, we have summarized some of the issues regarding TCFD disclosures from the perspective of companies that are doing the reporting. The use of TCFD disclosures is still nascent therefore more research into how the end users use the information reported in TCFD disclosures will help shape its evolution. It will be pertinent to understand how the various end users such as financial institutions and retail investors use the information provided in TCFD disclosures to assess climaterelated risks, and their valuation of companies [5]. We should also take a step back and look at the big picture and understand how TCFD disclosures influence public policies and vice versa, after all for the TCFD disclosures to achieve its full utility, it is imperative that the TCFD disclosures should not operate in silo [6].

While the TCFD disclosure guidelines are instructive, it is still a stretch for companies to apply them to their reports so that these are useful and concrete. Currently, the benefit of the TCFD disclosures is debatable as users of the TCFD reports felt that only the strategy and metrics and targets components in the TCFD disclosures are the most informative. The recommendations for a more worthwhile company's TCFD report include encouraging the sharing of best practices in terms of quality and quantity of disclosures, soliciting the feedback of TCFD users in identifying topics and areas that are pertinent for disclosure. In addition, the report should spur companies to incorporate scenario analyses to illustrate risks and opportunities that are associated with increasing temperature and explain how their businesses are equipped to handle the transition to net-zero carbon emission.

In terms of reporting format, a standalone sustainability report might make it easier for readers to jump right into the pertinent sustainability information, as evident from CDL's report. It is also important that sustainability information relevant to the TCFD disclosures framework be organized in a coherent manner so that readers will not have trouble perusing that information. Finally, most companies have filled up the sections of the TCFD disclosures in a manner that reads more like a laundry list and doing so does not allow the readers of such reports to learn about the sustainability commitments and preparedness of the organization. Rather, organizations should try to dig deeper and provide rationales for identifying certain components as key climate risks and justify the course of actions that they will take to mitigate the impact that climate risks will have on their businesses. Companies should also get acquainted with the climate scenarios as their deftness at climate scenario analyses will help their investors paint a better picture of their preparedness in managing and integrating future climate uncertainties into their business plans.

Companies face challenges in reporting sustainability information related to climate scenarios, strategy, and standardized targets and metrics. It is imperative that companies work together with TCFD by providing feedback on the obstacles that they face when it comes to reporting. TCFD has developed guidance on conducting climate-related scenario analysis and clarify elements of the TCFD disclosures following feedback from users. TCFD actively seeks feedback through public consultation and companies should get involved so that they can make the TCFD reporting work for them. Apart from understanding the issues that companies when reporting with the TCFD, we should also seek to find out how investors use the information from the TCFD and how TCFD reporting influence public policy.

In summing up, even while the TCFD disclosure guidelines are instructive, it is still a stretch for companies to apply them in their reports. Even while the benefit of TCFD may be less obvious, it is clear that the world of stakeholders, particularly investors, have placed an increasing emphasis on climate change. It is important to note the critical keyword in TCFD - "financial". It is all about the business bottom line.

\section{References}

1. Financial Stability Board (2017) Recommendations of the Task Force on Climate-related Financial Disclosures.

2. Financial Stability Board (2020) Task force on climate-related financial disclosures: 2020 Status report.

3. Loh L, Tang M (2021) Sustainability Reporting Review. Singapore Exchange and Centre for Governance and Sustainability, NUS Business School. 
4. Loh L, Singh A (2020) Corporate sustainability reporting in ASEAN countries. ASEAN CSR Network and Centre for Governance and Sustainability, NUS Business School.

5. O Dwyer B, Unerman J (2020) Shifting the focus of sustainability accounting from impacts to risks and dependencies: Researching the transformative potential of TCFD reporting. Accounting, Auditing \& Accountability Journal 33(5): 1113-1141.

6. Edwards I, Yapp K, Mackay S, Mackey B (2020) Climate-related financial disclosures in the public sector. Nature Climate Change 10: 588-591.

Your next submission with Juniper Publishers will reach you the below assets

- Quality Editorial service

- Swift Peer Review

- Reprints availability

- E-prints Service

- Manuscript Podcast for convenient understanding

- Global attainment for your research

- Manuscript accessibility in different formats ( Pdf, E-pub, Full Text, Audio)

- Unceasing customer service

Track the below URL for one-step submission https://juniperpublishers.com/online-submission.php 